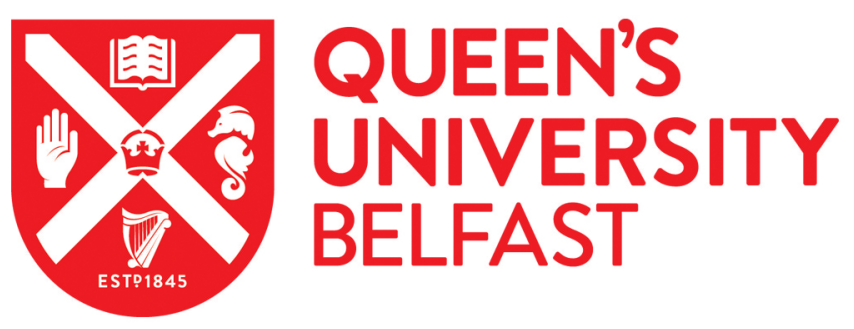

\title{
Recognition, Authority Relations, and Rejecting Hate Speech
}

Whitten, S. (2019). Recognition, Authority Relations, and Rejecting Hate Speech. Ethical Theory and Moral Practice, 22, 555-571. https://doi.org/10.1007/s10677-019-10003-z

\author{
Published in: \\ Ethical Theory and Moral Practice
}

\section{Document Version:}

Peer reviewed version

Queen's University Belfast - Research Portal:

Link to publication record in Queen's University Belfast Research Portal

\section{Publisher rights}

(C) 2019 Springer Nature Switzerland AG.

This work is made available online in accordance with the publisher's policies. Please refer to any applicable terms of use of the publisher.

\section{General rights}

Copyright for the publications made accessible via the Queen's University Belfast Research Portal is retained by the author(s) and / or other copyright owners and it is a condition of accessing these publications that users recognise and abide by the legal requirements associated with these rights.

Take down policy

The Research Portal is Queen's institutional repository that provides access to Queen's research output. Every effort has been made to ensure that content in the Research Portal does not infringe any person's rights, or applicable UK laws. If you discover content in the Research Portal that you believe breaches copyright or violates any law, please contact openaccess@qub.ac.uk. 


\section{Recognition, Authority Relations, and the Impact of Hate Speech}

Abstract A key focus in many debates surrounding the harm in hate speech centres on the immediate subordinating impact hate speech has on its victims. Under such a view, and provided there exists a requisite level of speaker authority a particular speech situation, hate speech can be conceived as a direct act of subordination, rather than as the mere expression of hateful ideas. Missing from these conceptions, however, are the ways in which intersubjective, recognition-sensitive relations influence the kind of harm likely to result from such an act. This paper aims to fill this theoretical gap, through examining the ways in which victims recognize the normative authority of hate-speakers to make claims upon them. As I contend here, understanding the recognitive nature of such acts helps to explain those cases in which hate speech fails to deliver the status-ordering intentions of the speaker. Utilizing this enhanced understanding, I reflect upon one particular real-world example of hate speech, in which the target rejects the status-ordering claims made upon her. In the last section, I propose a general institutional outlook aimed towards aiding would-be victims of hate speech to respond to such attempts at normative authority exertion.

Keywords Hate speech; Recognition; Authority; Langton; Racism; Speech-act theory

\section{Introduction}

Recent scholarship in hate speech theory considers the role authority relations play in the resultant impact certain forms of speech has on some of the most vulnerable members of society (Langton 2012). Operating under an abstract definition of 'hate' speech, as opposed to the more narrowlydefined conceptions found in legal definition, these accounts focus on the kind of expression that directly impacts the status of a defined identity group ${ }^{1}$. With such a definition in mind, these debates have attempted to unpack the nature and harm of acts as diverse as cross-burning, pornography, pamphleteering, newspaper headlines, and words published on social media ${ }^{2}$. Utilising a speech-act theoretical framework, and taking inspiration from the work of Austin (1962), such works also aim to address the central position speaker authority holds in contributing to the harmful impact of acts of these kinds. The range of potential harms experienced by victims is vast, and includes, among other things, an immediate threat to social status (Langton 1993, 1998; MacKinnon 1991, 1993, 2000), the perpetuation of disparaging social stereotypes (Matsuda, 1989), the emotional and physiological impact of fear and threat to physical self (Delgado 1982), the contribution to a hostile living environment (Waldron 2012) ${ }^{3}$, and the associated 'silencing' effect, which threatens an affected

\footnotetext{
${ }^{1}$ Here, we can put aside definitions that depend solely on identifying certain characteristics of the speech involved. Some identify hate speech by tracking complaints by a victim, usually through defining the harm in terms of psychological damage. Others, however, are concerned with hateful intent on the part of the speaker. Though these features often accompany the status-denigrating described in this thesis, they are not by themselves sufficient markers of an instance of hate speech.

${ }^{2}$ In-keeping with common-usage in the field, this paper is not aimed at providing a definition of hate speech, nor is it aimed at identifying criteria of certain speech-acts which make them worthy of legal restriction. Instead, the term 'hate speech' is used as a 'catch-all' term to describe those forms of speech that perform the function of direct subordination, in the manner described by the Langton/critical race theory perspective.

${ }^{3}$ Though he doesn't use the same speech-act language as Langton et al., it would be imprudent not to mention the relative absence of Waldron's work in the present discussion. Concerned largely with how certain publishable forms of hate propaganda contribute to the toxic visual climate of society, and how the existence of such a social backdrop contributes to the second-class citizenship and threat to assurance of affected groups, Waldron's approach reveals a timely gap in the US jurisprudence literature. However, as we will see in this paper, Waldron's analysis, in a similar fashion to Langton's, fails to offer a concrete framework capable of identifying and distinguishing between those 'grey area' cases of harmful speech act, most particularly those which may be categorized as offensive, yet non-regulable forms of identity-based expression. Utilising common usage of the concept of offensive in this context, we can place under this heading those cases that continue to receive a great deal of public attention, such as racially-insensitive comedy, religious satire, quasi-political
} 
individual's capacity to respond or speak out against her attacker (MacKinnon 1993). Of particular significance, however, is the way in which the illocutionary impact of hate speech actually constitutes an act of subordination. It does so, according to Maitra, by "constituting norms that help to construct social reality for the subordinated group." (2012: 99) So, rather than 'merely' causing secondary harmful effects in its utterance, hate speech can be directly compared to an act of discrimination, through enacting subordination in its expression. It is this particular harm, according to the theorists above, that provides serious cause for concern. It is also through employing the speech-act framework that such arguments are used to dispel the notion that hate speech does not have the potential to bring about an immediate change in states of affairs in the same way as, say, a violent assault on another. Often used as a critique of First Amendment 'absolutism', which places racist and discriminatory expression firmly within the protected class of 'ideas', exposing the shortcomings of a strict speechaction separation thus aims to highlight the very real dangers of certain forms of speech on a vulnerable group's status in society, thereby making the case for a shift in perceptions of the harm suffered through certain forms of expression.

In order to distinguish an act of subordinating hate speech from other sorts of speech, and inkeeping with the Austinian typology, it is argued that an act of hate speech must be accompanied by certain 'felicity conditions', most crucially a level of speaker authority. As the commonly-cited speech-act theory example shows, a registrar requires the relevant authority in order to pronounce a couple as legally married, and a suitably-appointed individual must hold the requisite authority required in order to christen a ship. As we will see, however, attributing the relevant speaker authority in more 'informal' acts of potentially harmful speech remains problematic and difficult to discern, and continues to be a significant problem for utilizing the speech-act theoretical framework for the purposes of understanding hate speech. Along such lines, theorists such as Judith Butler (1997) have questioned the categorization of hate speech as an illocutionary act of subordination. Here, the complex cultural and social relations involved in an act of 'hate' speech render such acts unpredictable and fluid in nature. Such an attempt to identify a direct act of subordination, then, is considered an impossible and futile task. Though Butler's poststructuralist conclusions remain open to debate, her argument regarding the indefinite result of certain acts of hate speech reveals certain crucial problems with the claim that certain forms of speech are necessarily subordinating in nature. As this paper argues, then, we must consider a further dimension to the already-considered felicity conditions outlined by the speech-act typology: the forms of intersubjective, recognitive exchange at play during an act of speech. Through unpacking a particular real-world example, we can uncover those recognition-sensitive authority relations that are currently absent in the Langton/critical race approach to understanding the impact of hate speech.

With these considerations in mind, this paper will be structured as follows. Beginning with a background exploration of the role of speaker authority in the dissemination of a hate-speech-act, we will consider how such relations inform and perpetuate certain status-ordering norms regarding treatment of oppressed groups. As we will see, this approach reveals certain crucial insights into how such speech-acts operate within the social backdrop of the surrounding lifeworld. Similarly, it will be shown how an examination of the place of speaker authority in the analysis of the resultant harm of hate-speech-acts remains an invaluable part of the practice of hate-speech theory, and must be adopted if we are to truly understand its effects and solutions. Following this, we will consider one notable gap

allusions to certain prominent global issues such as immigration or terrorism, and the kind of sexist tropes commonly associated with the popular music industry. Under a close reading of both Langton and Waldron, such cases would not fit the criteria generally associated with an act of hate speech. What the increased consciousness-raising around such forms of expression reveals, however, is that something harmful may be going on in some of these cases, in particular in their capacity to inform and perpetuate certain kinds of behaviour towards members of oppressed groups. Under the analysis considered here, then, we must take a broader approach towards examining the wider social and normative context of expressive conduct, and consider how such contexts can lend certain generally blithe expressions of bias authority depending on their position within these contexts themselves. 
in this hate-speech-act typology- one that can be characterized as an oversight into the key role that surrounding recognition of normative expectations and standards of behaviour play in the expression of certain speech-acts. Here, we see how Langton's claim concerning the acquisition of non-formal speaker authority casts the net too wide, thereby missing crucial context-laden aspects of hate-speech that could be utilized towards the creation of mechanisms of counter-speech in certain cases. This blind-spot will be further examined through the lens of a particular case study, which will then be unpacked from a recognition-sensitive, first-person perspective. Examining the authority relations and norm-governed nature of an act of hate-speech allows us to consider how such experiences play out within a particular social and cultural context, and reveals how the resultant status-ordering effects are heavily dependent upon this complex interplay of social rules, expectations, and the communication of reactive attitudes between individuals in society. To round off this exploration, I make a preliminary attempt to sketch potential practical solutions to the perpetuation of harmful, statusordering norms through enabling the rejection of authority claims made upon victims by hatespeakers.

\section{Speech-act theory, authority relations, and the status-ordering effects of hate speech}

In addition to the psychological and physiological impact experienced by victims of hate-speech-acts, many theorists cite the immediate subordinating harm hate speech has on victims (Langton 1998; MacKinnon 1993; McGowan 2005; Delgado 2009; Matsuda 1993). Such speech-acts, along these lines, directly reinforce and perpetuate the norms surrounding the relative social status of individuals from oppressed identity groups. The harm, then, lies in this direct subordination of status and the perpetuation of a negative and hostile climate for those affected. As a consequence of this disparaging normative backdrop, they are forced to come to terms with living in a world in which they are classed as second-class citizens in the eyes of others. Conceptualizing this particular harm using the language of recognition, we can refer to this loss of status as a denial of "recognition respect", where recognition in this sense refers to an individual's experience when they "have other persons take seriously and weigh appropriately the fact that they are persons in deliberating about what to do." (Darwall 1977: 38) The expression of hate speech, then, can be considered as a clear act of misrecognition. The hate-speaker is expressing to his victim know that he does not consider him of equal worth in his deliberations, and that he does not tailor his actions in light of their claims. In short, he is letting victims know through his speech that they are not worthy of respect, and as such do not hold equal status as human beings in receipt of moral consideration. Such status-ordering is thus a key feature of harm-focused accounts of hate speech, and, though often not expressed through the language of recognition, is a central issue for those concerned with eradicating the ills of hate speech in society.

To Langton and others, then, the significant impact hate speech has on victims can be conceptualized not merely as expression but as a speech-act, and one that reinforces and perpetuates certain kinds of harm in a comparable way to more 'tangible' forms of discrimination or identitybased violence. Making use of J. L. Austin's speech-act theory (1962), we see how such hate-speechacts operate according to the distinction between illocutionary and perlocutionary speech-acts. Under such a typology, we see how an illocutionary act does something in its expression. To use several commonly-visited examples, we see how stating 'I do' in a wedding ceremony actually constitutes the legal act of marrying, the statements made by a judge in the courtroom comprise the act of sentencing a defendant, and the swearing of an oath during a citizenship ceremony constitute a tangible and definitive act aimed towards a particular legally-binding outcome. In contrast, we can identify certain perlocutionary effects of a speech-act, where these effects relate to the potential secondary outcomes of an illocutionary act. So, for instance, the perlocutionary effect of saying 'I now sentence you to five years in prison' is likely to be the shocking and saddening of the defendant. These secondary perlocutionary effects are thus dependent upon the nature of the illocutionary act in question. The strength and shape of the perlocutionary effects of such a speech-act, therefore, rely on the 
constitutive nature of the speech-act, how it impacts those who are subject to it, and, consequently, how the hearer responds to and interprets the force of the act itself. It is with this Austinian typology in mind that Catherine MacKinnon (2000) describes the harm suffered to the normative status of women through the widespread prevalence of pornography. According to such a view, not only does pornography provide a visual representation of the subordination of women, which in turn delivers certain perlocutionary outcomes in the form of increased gender-based violence and sexual assault, but the expression involved in the pornography itself actually constitutes an act of subordination. Contrary to previously-held discussions surrounding the harm of hate speech, then, this framework considers not only the 'propaganda' impact of such speech, in which others are recruited or encouraged to engage in discriminatory practices, but the immediate subordinating impact of an act of hate speech. This view, then, marks a clear difference between those who believe that hate-speech has the potential to produce harmful effects in future, and those who hold that the act itself actually subordinates those affected.

What kind of felicity conditions, then, are required in order to imbue a speech-act with its intended meaning? As mentioned above, an act must be accompanied by the appropriate felicity conditions in order to have its intended effects. This includes both the intention of the speaker, assuming that their choice of words and manner of speaker were informed by certain surrounding communicative conventions, as well as the conventions of the surrounding speech-situation in which the utterance was made. So, saying 'I do' during a wedding ceremony depends on displaying a clear understanding of the semantic content of the words spoken, as well as an intention to use them to perform the act of marrying. Second, certain specific surrounding norms must be present in order to provide the felicity conditions necessary for my statement to be successful. In the very specific circumstances of a wedding ceremony, then, this involves the presence and prompt of a registrar at a specified time in the proceedings, my relevant role occupation as one part of a couple known by the registrar to be taking part in this particular wedding ceremony, as well as the legal conditions required for my statement to have effect, such as my informed consent to marry, the non-married status of myself and my partner, and the official status and authority of the registrar to oversee and register the ceremony. Were any of these conditions absent during my statement, the illocutionary act of marrying would not be successful. In regards to an illocutionary act of hate speech, then, we must examine the appropriate felicity conditions required to supply the act with subordinating force. This proves relatively simple to discern in cases where, like the pronouncements of the judge or registrar, the utterance directly correlates with a change in states of affairs. Using the example of an apartheid-era South African legislator, Langton (2012) examines the illocutionary and normative order-building impact of an act of racist hate-speech. When the legislator makes a public statement that 'Blacks are not permitted to vote' they are not merely expressing their racist sentiments concerning black citizens of South African society, but are actually committing an act of discrimination and subordination. As an illocutionary act, the legislator is thus directly placing black citizens within a diminutive social status. Like an act of discrimination found in, say, the racially-motivated refusal of service to a black citizen, the statement made by the legislator also constitutes a subordinating act of normative orderbuilding, this time through the medium of discourse. The felicity conditions here, then, depend largely upon the legislator holding the relevant authority to create such a change in the law. What about cases, then, where the utterance does not result in the same changes in the law?

Here, Langton notes how 'non-official' hate-speech can also produce an immediate statusordering effect to the one produced by the legislator's words (Langton 2012: 86). In terms of what hate speech does in its execution in such cases, then, it can inform and justify existing norms that remind citizens of the unequal status of black individuals. According to such a view, a racist is not simply expressing his hateful views through his speech, but is actually placing black people in a diminutive social position through his expression. The perlocutionary effects of such an act, then, involve persuading or encouraging others to treat blacks with less respect than those afforded to whites. Such speech thus appears to strengthen norms of racism through corroborating with their underlying intentions. When we see others making a statement about the inferiority of a particular 
group, we may come to include such thoughts in our deliberations about how we should act and treat the group in question. This is only strengthened, as Langton notes, when the speaker holds the relevant authority to make such a judgement about the norms in question. So, although the South African legislator does hold the requisite authority required to actually change voting laws, we might imagine a circumstance in which a local community leader makes a statement condoning the unequal treatment of blacks. If, for example, the leader publicly declares that 'black people cannot be trusted', we can see how, despite the inability of the leader to actually change the law himself, his statement no doubt is accompanied by a great deal of speaker authority in regards to the justification of certain attitudes and treatment of blacks in society. In addition, and apart from the assaultive impact of disparaging messages and perpetuation of stereotypes, hate-speech thus is also directed towards those outside of the relevant identity group, in the form of propaganda (Tirrell 2013: 208). The aim of such acts, then, is to reinforce the hierarchical normative-ordering of the hated group. So, although the distribution of an anti-Semitic publication such as Der Stürmer served to remind Jewish citizens of their second-class status, the main goal of such works was to further entrench anti-Jewish sentiment among the rest of the population, thus further reinforcing both an 'Us and Them' binary and contributing to the deeply hierarchical nature of Nazi German society (Stanley 2015: 251).

\section{Intersubjective recognition, authority relations, and hate speech}

As per the tradition propounded by theorists as varied as Axel Honneth $(1995,2007,2012)$ and Charles Taylor $(1989,1994)$, among others, recognition theory draws our attention towards the value of our intersubjective relations in the development of individual autonomy and the positive selfformation of agents. Without an adequate and suitably enriched experience of recognition from others, so the theory goes, we suffer a profound harm to the equal status we enjoy as members of the moral community. Absent recognition from others, we experience the effects of deep disrespect, something which impacts all areas of our lives, from our capacity to engage with others as equal participants in the exchange of claims-making, to our self-understanding as persons worthy of certain treatment from others. For the aims of this paper, then, we will consider this individualist, first-person conception of intersubjective recognition over other, more group-identity based forms of recognition. Though the two are related, this paper focuses on the status-ordering harm to individuals at the hands of hate speech, and so we will, for present purposes, be putting to one side questions of group-centred forms of recognition.

With the central role of recognition in mind, we can see how this dialogical aspect of identityformation leaves much of the responsibility for our sense of self in the hands of the surrounding community. Our access to a healthy recognitive status is thus highly dependent upon the background structures and normative conditions shaping the social backdrop of our interactions. Persistent exposure to negative stereotypes and representations regarding our membership of a particular identity group, then, has a direct negative impact on our recognitive status and sense of self. In the kind of subordination found in both explicit forms of hate speech and in more implicit attempts of hierarchy entrenchment, victims must consistently fight to hold on to their sense of self-respect, without which they may struggle to demand certain treatment from others effectively. As regards to our discussion regarding the legitimation of authority described in the first section of this paper, however, we also find that intersubjective relations play an in dispensable role. For, as is a key notion in theories of recognition, we must recognize others as holding the relevant authority to make claims or judgements upon us regarding our relative social status. It is with this consideration in mind that Darwall (2006) extends his conception of recognition respect to include the notion of 'secondpersonal respect', in which we must consider our reciprocal, claims-making relationship with others when we engage in moral address. Under such a view, we each recognize all others as having certain claims upon us, where those claims relate to the mutual recognition of our standing as equal members of the moral community. Darwall thus extends Austin's typology to include certain "normative felicity conditions", where these concern "what must be true for second-personal reasons actually to 
exist and be successfully given through second-personal address." (Darwall, 2006: 4) Fundamentally, we must recognize others as holding the normative authority to make moral claims upon us. It is in this capacity that we are thus held accountable for our actions towards others, and must consider ourselves answerable to any moral claim made against us. How, then, do such forms of interpersonal address operate in the exchange that takes place between hate-speaker and victim?

On a basic level, we can identify a minimal level of recognition that the hate-speaker has for a victim. In order to harm the victim in the status-ordering way intended, a hate-speaker must recognize the victim as having the capacity for moral address. This requires that they are capable of understanding the claims made against them, and that they are aware of the conventions surrounding the semantic content of the utterance. However, it is clear that, for the immediate, status-ordering subordination to take effect, the victim must also recognize the normative authority of the speaker as legitimate in making such a claim. This, as we shall see, depends on the nature of the roles of the individuals involved, as well as the practices surrounding that particular role. Along such lines, we can make use of Hershovitz's definition of authority as "a feature of roles embedded in practices." (2011: 25) Under such a conception, we can understand the mutual expectations at play in, for example, a student-teacher relationship, where the student recognizes the authority of the teacher as legitimate when they make certain claims upon them. Under the relevant conditions of the classroom situation, then, the student recognizes the authority of the teacher to make certain states-of-affairs changes in the classroom that would not be appropriate in most other contexts. It is thus the nature of the student-teacher relationship, the relative role functions, and the surrounding practices, that provide the teacher with the requisite authority to make certain demands upon her students. The kinds of demands involved in the student-teacher relationship, however, differ from the demands involved in the second-personal exchange outlined by Darwall. For, apart from the role-dependent authority relations of the student-teacher relationship, the student and teacher are both equally in demand of second-personal respect to one another. This means that, were the teacher to act in a way that undermined the basic respect afforded to the student, the student has the right to hold the teacher to account for her actions in the form of a reactive attitude, where reactive attitudes "presuppose the authority to demand and hold one another responsible for compliance with moral obligations." (Darwall, 2006: 17)

In cases of hate speech, then, we must consider how the relevant roles and practices operate to provide the act with authority, itself essential for the act to have an immediate, status-ordering effect. This is even more important in cases of informal speaker authority, where the hate-speaker holds no 'official' power to enact legal changes that may impact the relative social status of a victim. For the illocutionary impact of a hate speech act to be successful, then, victims must recognize the speaker as having the legitimate authority to enact such a change in social status, despite the lack of formal changes in states of affairs. To illustrate this point, we are reminded of the non-official, informal statement made by the community leader in the previous section of this paper. When he claims that 'black people cannot be trusted', he is making a claim from his position of informal authority in the community. If we consider the process of claims-making described above, we can consider the roles at play as involving an exchange between the leader himself, the surrounding white population, and the black population of the community. He is making his statement in his capacity as a representative, and this role provides him with the authority required in order for his statement to have meaning. However, is it necessarily the case that the speech he uses is illocutionary in nature? Here, it is clear that the leader has some sort of standing, and so his words will most likely influence the norms of the surrounding society. His fellow white racists, moreover, will clearly recognize this man's authority to speak for the community. The role-relation between leader and community members thus dictates the capacity for which the leader has authority in making his statement. However, it is not so clear that the same applies to the black population, as these are the individuals who are considered victims of the immediate subordination of the leader's words. For his words to be recognized as legitimate, the black population must recognize the legitimacy of the role the leader holds as a community representative. They (presumably) do not recognize him in this capacity, and so do not see his words 
as legitimate. It is thus not so clear that the words spoken, though they clearly produce harmful perlocutionary effects, are directly subordinating in nature, provided the collective black community reject the legitimacy of the leader's authority. This highlights the idea that satisfaction of the felicity conditions required for immediate subordination is not a forgone conclusion, but is highly dependent on how victims recognize the relevant normative authority to make certain claims upon them and their status.

One possible rejoinder to this claim against the illocutionary nature of hate speech lies in Langton's discussion of 'presupposition accommodation' (1993), wherein speaker authority is acquired through the relative non-intervention of the surrounding others in a speech situation. Borrowing the concept from Lewis's notion of 'language games' (Lewis, 1979), we find here how racial superiority can seep into the common consciousness of society through lack of 'pushback' or retaliation whenever hateful words or statements are introduced into public discourse. This is a common tactic used by tabloid newspapers, whose use of thinly-veiled prejudices is often used to induce emotive and fear-driven associations concerning certain sections of the population. The increased prevalence of unquestioned assumptions regarding the targeted group thus become part of the social landscape of the community. It becomes the 'norm' to view blacks through the lens of criminality and distrust, and to be fearful and suspicious of Muslims (Stanley 2015: 139). This leads to what is referred to as a 'norm cascade', in which certain attitudes towards a particular group feed off the assumption that everyone else in the surrounding community also holds those fears (Sunstein 1996). This phenomenon often leads to the proliferation of profound identity-based divisions in society, and as thus is a well-established tool of those seeking to further divide communities along such lines (Sunstein 2009). The slow-burn effect of constant negative normative-ordering thus has a similar effects to more explicit acts of hate speech, yet, unlike explicit verbal assaults, cannot as easily be targeted by legal measures to ensure its prevention. Similarly, both the exercise of authority in explicit forms of hate speech and in the 'slow-burn' kind of propaganda both depend upon certain existing sentiments regarding the targeted group in question.

Though this phenomenon plainly exerts very real harmful effects on the social position of targeted groups, it is still not clear that these forms of expression constitute an illocutionary act of subordination. In fact, the very incremental nature of such forms of speech appear to be directly correlative to perlocutionary effects found in the persuading and inspiring of hearers regarding the relative social status of the targeted group. In terms of the non-intervention of other individuals in the surrounding speech situation, this again needs to take into consideration the relevant roles and practices present. Again, we need not consider hate speech to be immediately subordinating in nature. Though the effects remain harmful, understanding more clearly this ambiguity serves to construct possible solutions to the norm-influencing effects of hate speech, without necessarily categorizing such acts as illocutionary in nature. Here, then, we will consider how such authority relations, intersubjective recognition, and harm operate in the case of a real-world example. Doing so will illustrate more clearly the myriad ways in which speaker authority remains open to interpretation, thereby rejecting the claim that silence instils hate speech with informal authority and thus satisfies the felicity conditions required for an illocutionary act of subordination.

\section{The example}

In February 2017, Scottish-Pakistani woman Sanaa Shahid and her four-year-old son were subjected to a racist attack on the London-Glasgow train by Alexander Mackinnon, a white UKIP supporter and former public schoolboy (Daily Record, February 2017). Expressing anger at encountering Shahid in the first-class carriage of the train, he went on the following tirade, stating:

"How did you get into first class? You don't deserve to be in first class...You should be in common class. In fact, you shouldn't be in this country at all." 
He then went on to say that,

"You don't deserve to be here. Bloody foreigners. Where were you even born?"

During the attack, Shahid reported that none of the other train passengers intervened. In response to Mackinnon, however, she filmed the encounter on her mobile phone, before calling the train manager and making a report to the police. The train manager, according to Shahid, was extremely helpful, as were the police who dealt with the case. PC Mark Mellenthin, the officer investigating the case, noted how Ms Shahid was "visibly distressed and shaken", with Shahid herself noting how the attack left her wary of using the train in future, and that her son was scared of future attacks. Following an appearance in court, Mackinnon was convicted of a racially aggravated public order offence and was fined $£ 1,154$ plus legal costs for the attack (BBC News, February 2017).

Unpacking this example using the speech-act and recognition frameworks described above, we encounter several different ways in which authority relations inform and perpetuate the subordination of Shahid and her son at the hands of Mackinnon. As noted at the beginning of this paper, the felicity conditions for a potential speech-act to have certain illocutionary effects involve both the intention of the speaker and the surrounding conventions or norms of the speech-situation itself. Under Catherine MacKinnon's and Langton's conception, the illocutionary act of the attacker's words actually constituted the subordination of Shahid and her son, provided these particular felicity conditions were in place. This includes shared understanding of the semantic content of the tirade, the relevant authority of the speaker in making his statement, and the surrounding conventions regarding the meaning of the words he uses. Here, it is clear that Shahid and the speaker both share an understanding regarding the speaker's views. It is clear from his words that he is targeting Shahid on the basis of her ethnicity and religion, that he is expressing his view that she does not belong in the same social space as him, and that he disrespects her on account of her perceived ethnicity. Considering the surrounding conventions, we can look towards the unfortunately common occurrences of hate speech of this kind that take place on public transport. In contrast to the wedding ceremony example, in which certain highly specific circumstances were required to satisfy the requirements of the act's felicity conditions, the same specific conditions need not apply for an act of hate speech to have the intended illocutionary effect, though, as we shall see, these condition can more or less impact the resultant impact of the act itself. At the time of the attack, however, the UK was suffering from an increase in the number of reported instances of racially and religiously aggravated offences, with a large proportion of those recorded taking place on public transport. As a close-quarters site of public interaction, in which individuals encounter and share a comparably intimate social space with strangers from all walks-of-life, public transport remains an unfortunately common location for racial and religious harassment. It is clear, then, that Shahid understood the expression of Alexander Mackinnon, that she knew it was racially motivated, and that she felt upset and scared by the attack. However, this only points towards the perlocutionary effects of the act, and does not tell us whether or not Mackinnon was successful in performing the illocutionary act of subordination in his ranting. Here, then, we must examine more closely the authority relations at play in this exchange, in particular how Shahid recognizes and responds to the authority of Mackinnon in her understanding of the act.

As mentioned above, Shahid and her son were both emotionally impacted at the time of the assault, but for the actual act of subordination to take place, certain other conditions need apply than the ones we have so far mentioned. The mutual understanding of the sentiments of Mackinnon reveals that Shahid recognizes the authority of Mackinnon in some basic way. That is, she recognizes him as a fellow person who makes claims on the basis of their status as a human being of equal moral worth. She thus may recognize the authority of Mackinnon to make claims on others, no matter what those may be. However, it is not clear that Shahid may necessarily recognize Mackinnon's expression as representing anything regarding the authority of the content of his words. The claims made by Mackinnon, however, did not imply any such official authority. Instead, he is intending to assert his 
authority in his role as a white, British person, and possibly even his authority in terms of class status. His words, including the statement that Shahid is a 'foreigner' who 'doesn't deserve to be here' both express the view that those outside his identity group are not welcome in the shared social space and imply that such views are shared by his fellow citizens. He is thus attempting to exert authority in the form of communicating to Shahid that those of Pakistani origin are not welcome in Britain, as well as practical authority in the form of telling her she must leave the carriage.

From the perspective of Shahid, then, she may come to believe certain things from this attempt at authority-exertion. She may take at face value the claims made by Mackinnon, accepting his authority regarding the general stance of the surrounding British community. She may also accept Mackinnon's authority when he expresses his anger at her presence in the carriage, and she may have chosen to move carriages. It seems, then, that for the felicity conditions to be satisfied regarding the illocutionary classification of Mackinnon's abuse as an act of subordination, Shahid must recognize the authority of Mackinnon in attempting to place her in a diminutive social status. As we saw in the apartheid legislator example, speaker authority need not be 'formal' in the legal sense to have such an effect on the relative status of targeted identity groups. However, there seems to be more going on here in terms of the recognition of authority claims that we must consider before we can say for certain that Mackinnon's words can be categorized as an illocutionary act of subordination. Here, we can remind ourselves of Langton's discussion of presupposition accommodation, in which a speaker is granted informal authority through the 'default adjustment' of a particular communicative exchange. Crucial in this context, then, is the way in which the surrounding persons at the time of the attack respond to the abuse. According to Shahid, there were "10-12" people present who were witness to the abuse, though none of them intervened. This lack of response is, according to the notion of presupposition accommodation, a perfect example of an instance in which informal speaker authority is acquired, and the intent of the speaker to enforce subordination is legitimized through omission. From this omission, it would be reasonable for Shahid to presume that the entire carriage, and perhaps a large proportion of the British population, disapproved of her presence in British society as a member of a particular non-white ethnic group. However, for this to have the intended subordination effect, it nonetheless remains the case that Shahid must recognize Mackinnon's authority as legitimate, a consideration that is missing from Langton's account. Along such lines, there may be several reasons why Shadid would not recognize the authority of Mackinnon as legitimate. For example, she may have perceived that he was under the influence of alcohol and thereby 'didn't mean' what he said. Shadid may have also interpreted the situation as one in which fellow passengers were, rightly or wrongly, simply 'minding their own business'. While not a moral defense for their non-intervention, this appears to be a common occurrence for many. So, while the passengers may have considered Mackinnon's words highly objectionable, they may have been afraid of intervening for fear of becoming a target of abuse themselves. Non-intervention on the part of fellow train-goers, then, does not appear here to necessarily amount to endorsed adjustment.

Further, several other features of the surrounding context provide rival authority claims in the opposite direction to the one Mackinnon ascribed to himself and the surrounding community. First, Shahid, as a British-born citizen, later told the media that "I've lived in Scotland all my life and nothing of this nature has ever happened to me" (Daily Record: February 2017), suggesting that she had not suffered this sort of racist attack before. This somewhat de-legitimizes the attempt at the hands of Mackinnon to assert his authority as a white, British person. In addition, the intervention of the train manager, who told Mackinnon to leave the train at the next stop, presents a rival authority regarding the social status of Shahid in this scenario. The zero-tolerance train policy against racism clearly exerts a substantial form of formal authority over the correct interpretation of the norms of the surrounding community. Here, then, both the train policy itself, and the following police investigation and conviction, act as the overarching authority regarding the relative social status of those of Pakistani origin in British society. It is here that the illocutionary impact of Mackinnon's words fails to act as a form of subordination in the way described by Langton's approach. In addition, and using Hershovitz's terminology, we can consider Shadid's recognition of the relevant role occupied by 
Mackinnon, as well as its associated practices, to determine whether or not Shadid considers Mackinnon's authority as legitimate. Here, as mentioned above, Shadid probably holds a minimal level of recognition for Mackinnon as an equal member of the moral community. This means that she recognizes him as having a certain reciprocal standing in relation to herself, as an individual who has the normative authority to make certain second-personal claims on all others. Based on the nature of the train carriage situation, and on her response to the attack, this is the only relevant role Shadid is likely to recognize as legitimate. She need not accept his attempt at exerting additional authority in regards to his self-assigned role as a white, British, upper-class male, as this requires a non-normative acceptance of a particular role relationship that she is not morally obligated to partake in. As such, Shadid here rejects Mackinnon's attempt at enforcing a particular role relation with her, thus delegitimizing his authority and not supplying the relevant felicity conditions required to satisfy the illocutionary categorization of his utterances.

With these considerations in mind, the next section will consider whether we can utilize these findings towards the aim of reducing the harmful perlocutionary effects of hate-speech through undermining the attempts of hate-speakers to exert this authority over a particular speech situation.

\section{Providing counter-narratives as a response to the struggle for normative authority}

As we have seen so far, hate-speech need not result in the kind of immediate subordination described by Langton and the like. This finding, however, does not provide a practical solution to those cases in which hate speech results in (often devastating) perlocutionary effects for those who are targeted. What this brief section does, then, is to highlight the way in which we must provide substantial institutional responses to a hate-speaker's attempt at exerting normative authority over a speech situation.

In response to the discussions in this paper, then, we can ascertain the following claims regarding the link between speaker authority, role recognition, and the resultant status-ordering and subordinating harm of hate speech: i) in cases in which a hate-speaker holds the relevant 'formal' authority to legally change states of affairs regarding the relative social status of targeted individuals, we can correctly state that the felicity conditions required for the act to be considered illocutionary in nature are satisfied; ii) in those cases in which legal authority is absent, but authority exists as a function of the speaker's role, both parties must recognize the role and surrounding practices as legitimate in order for the claim to have its intended, immediate impact; iii) where an attempt at exerting authority in the form of status-ordering takes place, we can describe this is a failure for the speaker to acknowledge the second-personal claims of the victim, thereby making these claims automatically illegitimate. Despite the illegitimacy of such attempts at exerting normative authority, the harmful attempts involved in its execution remain a central problem for affected individuals. What states must do, then, is to undermine these attempts made by hate speakers at subordinating their targets.

First, and as we saw in the example shown above, we see how Shahid was able to easily report her attack to the authorities, where she then received swift and sufficient attention in response to her case. The intervention of the train driver, the police taking seriously her claim, and the conviction of Mackinnon for his abuse all provide a counter-narrative regarding the legitimacy of the authority of Mackinnon in British society. What this shows us, then, and paraphrasing Waldron (2012), is that individuals must be provided with the assurance that they are considered equals in society and that their status is protected by the state. Departing from Waldron, however, we can consider those other harmful attempts at exerting normative authority that move beyond the grasp of the law. Here, I refer again to those 'slow' forms of status-ordering that proliferate online forums and the mass media. And, following the recent rise in reported cases of hate crimes against minority individuals, it is clear that we must attempt to combat these, often more insidious, forms of statusordering that form the normative backdrop of our society. 
One attractive response lies in combating the emergence of 'echo chambers' described in the work of Sunstein $(2001,2009,2017)$. Here, individuals are drawn to and congregate around those groups that shield them from the worldviews of others, potentially performing a dangerous function of nurturing partisan and paranoid thinking. It is within these closed groups that a struggle for normative authority often reveals itself, and so we must make a concerted effort to establish and nurture those forms of common-ground media in order to avoid the growth of harmful and socially debilitating factions. Providing a highly-public media platform in which all citizens are welcome re-asserts the equal status of all individuals, and strengthens the will of victims against repeated attempts at subordination and negative status-ordering. Common-ground media plus provides a rival normative authority to the kind offered by a highly-partisan echo chamber, encouraging individuals to relate to and engage with one another over their shared experiences in society, rather than choosing to divide over perceived differences. Over time, the norm-changing nature of decreased social division will further equip vulnerable individuals with the psychological tools required to engage in counter-speech effectively, as the closely-available and highly-visible common authority regarding the equal status of all individuals will provide a much-needed assurance against attempts at exerting harmful normative claims upon them.

As a further response to the struggle for normative authority described above, we can also invoke Brettschneider's work on the expressive power of the state. Aware of the various practical shortcomings of European-style hate speech legislation, as well as the inadequacy of the US 'libertarian' approach to hate speech, Brettschneider's proposed method of 'democratic persuasion' offers a compelling response to the struggle of normative authority described above. Here, he rejects the notion that the First Amendment value neutrality principle best serves the liberal goals of equality and freedom of conscience. Aware that state silence in response to the proliferation of hateful ideas can often legitimize those viewpoints to the wider public, his method of persuasion calls for public disavowal of hateful ideas, though without the force of criminal sanction. Formulated as a method of 'speaking back', Brettschneider outlines several examples of the kind of state response that could be used to 'rob' hate speech of its power to subordinate certain individuals. Attempts to target the status of African Americans in US society, for instance, must contend with expressions made by the state reminding black individuals that their civil rights are considered worthy of protection. As such, public holidays and memorials commemorating the work of Martin Luther King Jr. aim to express the state's concern for the historical struggle of the black civil rights movement. Rather than potentially drawing attention to, and possibly creating martyrs out of, racist hate-speakers by introducing hate-speech laws, providing an alternative authority in the form of public recognition aims to re-assert the equal status of African American individuals. This method of democratic persuasion thus "robs hateful viewpoints of their possible outlaw allure, and instead publicly refutes them" (Brettschneider 2012: 24). This method of public condemnation of hate alongside the official reminder of equal status is therefore especially relevant to the kind of case-study outlined in the previous section. The authorityrelated felicity conditions necessary for an act of subordinating hate speech to be successful can, without the use of criminal sanction, face intervention in the form of competing authority claims. In this highly-connected age of social media, and despite increased exposure to hateful points of view, we can also see the potential for both state and non-state actors to provide a competing, statusaffirming counterweight to the views of would-be hate-speakers. As such, we see the internet as a space where individuals from historically-marginalised groups can have their voices heard and supported by like-minded others. This democratization of the public sphere also places additional pressure on public representatives to 'comment on' or respond to instances of hate speech, thereby reminding citizens from vulnerable groups that the discrimination they face is not widely-accepted and will not be tolerated in a society dedicated to securing the free and equal status of all its citizens.

\section{Conclusion}


The harmful potential impact of hate speech on victims is impossible to ignore. As I have shown here, however, the negative outcomes need not be immediately subordinating in nature. Whilst the illocutionary impact of changes in legislation operates as a form of action, it is not always clear that the required illocutionary felicity conditions are satisfied in cases in which such legal changes do not take place. As argued, when we consider the ways in which role recognition can instil authority into a given speech situation, we must consider how such relations operate from the perspective of the struggle for normative authority. Only then can we explain those cases in which attempted exertions of authority 'misfire' or fail to provide the requisite felicity conditions required in order for the hatespeech to have its intended effect.

Putting cases of formal authority to one side, however, does not negate the potentially devastating perlocutionary effects of hate speech. This is where we must provide individuals with counter-narratives to the emergence of harmful worldviews, which remind them of their equal status in society. Moreover, and beyond Waldron, this extends beyond the reaches of the criminal law, as these struggles for normative authority permeate all areas of social life. It is here where states must ensure an equal space for all to engage in communicative exchange with others, provided such spaces are accompanied by the reminder of the equal standing of all who choose to participate.

\section{References}

Altman A (1993) Liberalism and campus hate speech: a philosophical examination. Ethics 103: 30217

Altman A (2012) Freedom of expression and human rights law: the case of holocaust denial. In: Maitra I and McGowan MK (eds.) Speech and harm: Controversies over free speech. Oxford University Press, Oxford

Austin JL (1962) How to do things with words. Oxford University Press, Oxford

BBC news online (February 7 2017) Public transport fears of train racism victim Sanaa Shahid. Found at: http://www.bbc.co.uk/news/uk-scotland-glasgow-west-38891119. Last accessed 04/01/2018

Brennan G; Goodin R; Jackson F; Smith M (eds.) (2006) Common minds: themes from the philosophy of Philip Pettit. Oxford University Press, Oxford

Brettschneider C (2012) When the state speaks, what should it say?: How democracies can protect expression and promote equality. Princeton University Press, Princeton and Oxford

Butler J (1997) Excitable speech: A politics of the performative. Routledge, New York \& London

Crenshaw K et al. (eds.) Words that wound. Westview Press, Colorado

Darwall S (1977) Two kinds of respect. Ethics 88(1): 36-49

Darwall S (2006) The second-person standpoint: morality, respect, and accountability. Harvard University Press, Cambridge MA

Darwall S (2010) Authority and reasons: exclusionary and second-personal Ethics 120: 257-278

Delgado R (1993) Words that wound: a tort action for racial insults, epithets and name calling. In:

Crenshaw K et al. (eds) Words that wound. Westview Press, Colorado 
Enoch D (2012) Authority and reason-giving Philosophy and Phenomenological Research 89(2): 296332

Hershovitz S (2011) The role of authority. Philosopher's imprint 11: 1-19

Honneth A (1995) The struggle for recognition: the moral grammar of social conflicts. Polity, Cambridge

Honneth A (2007) Disrepect: the normative foundations of critical theory. Polity, Oxford

Honneth A (2012) The I in we: studies in the theory of recognition. Polity, Cambridge

Hornsby J (1994) Illocution and its significance. In: Tsohatzidia SL (ed) Foundations of speech act theory. Routledge, London

Langton R (1993) Speech acts and unspeakable acts. Philosophy and public affairs 22: 305-330 Langton R and Hornsby J (1998) Free speech and illocution. Journal of legal theory 4: 21-37

Langton R and West C (1999) Scorekeeping in a pornographic language game. Australasian journal of philosophy 77: 303-19

Langton R (2006) Disenfranchised silence. In: Brennan G; Goodin R; Jackson F; Smith M (eds.) Common minds: themes from the philosophy of Philip Pettit. Oxford University Press, Oxford

Langton R (2009) Sexual solipsism: philosophical essays on pornography and objectification. Oxford University Press, Oxford

Langton R (2012) Beyond belief: pragmatics in hate speech and pornography. In: Maitra I and

McGowan MK (eds.) Speech and harm: Controversies over free speech. Oxford University Press, Oxford

Langton R (2017) Is pornography like the law? In: Mikkola M (ed) Beyond speech: pornography and analytic feminist philosophy. Oxford University Press, Oxford

Lewis D (1979) Scorekeeping in a language game. Journal of philosophical logic 8: 339-59

MacKinnon C (1993) Only words. Harvard University Press, Cambridge MA

Maitra I and McGowan MK (2007) Limits of free speech: pornography and the question of coverage. Legal theory 13: 41-68

Maitra I and McGowan MK (eds.) (2012) Speech and harm: Controversies over free speech. Oxford University Press, Oxford

Maitra I (2012) Subordinating speech. In: Maitra I and McGowan MK (eds.) Speech and harm: Controversies over free speech. Oxford University Press, Oxford

Matsuda M (1993) Public response to racist speech. In: Crenshaw K et al. (eds.) Words that wound. Westview Press, Colorado 
McGowan MK (1993) Conversational exercitives and the force of pornography. Philosophy and public affairs 31: 155-189

McGowan MK (2009) Oppressive speech. Australasian journal of philosophy 87: 389-407

McGowan MK (2012) On 'whites only' signs and racist hate speech: verbal acts of racial discrimination. In: Maitra I and McGowan MK (eds.) Speech and harm: Controversies over free speech. Oxford University Press, Oxford

Mikkola M (ed) (2017) Beyond speech: pornography and analytic feminist philosophy. Oxford University Press, Oxford

Nielsen LB (2012) Power in public: reactions, responses, and resistance to offensive public speech. In: Maitra I and McGowan MK (eds.) Speech and harm: Controversies over free speech. Oxford University Press, Oxford

Raz J (2010) On respect, authority, and neutrality: a response. Ethics 120:279 - 301

Stanley J (2015) How propaganda works. Princeton University Press, New Jersey

Sunstein CR (2001) Republic.com. Princeton University Press, New Jersey

Sunstein CR (2009) Going to extremes: how like minds unite and divide. Oxford University Press, Oxford

Sunstein CR (2017) \#Republic. Princeton University Press. New Jersey

Taylor C (1989) Sources of the self. Harvard University Press, Cambridge MA

Taylor C (1994) Multiculturalism and the politics of recognition. Princeton University Press, New Jersey

The Daily Record (February 4 2017) Vile solicitor launches racist tirade against mum and young son on train. Found at: https://www.dailyrecord.co.uk/news/scottish-news/you-dont-deserve-here-bloody9753726. Last accessed 02/01/2018

Tirrell L (2012) Genocidal language games. In: Maitra I and McGowan MK (eds.) Speech and harm: Controversies over free speech. Oxford University Press, Oxford

Tsohatzidia SL (ed) Foundations of speech act theory. Routledge, London

Waldron J (2012) The harm in hate speech. Harvard University Press, Cambridge MA

West C (2012) Words that silence? Freedom of expression and racist hate speech. In: Maitra I and McGowan MK (eds.) Speech and harm: Controversies over free speech. Oxford University Press, Oxford 